\title{
EFFECT OF DIFFERENT STRAIN ROUTES ON MECHANICAL PROPERTIES AND MICROSTRUCTURE OF COPPER
}

\author{
Seyed Mohammad Javad Hoseini ${ }^{1}$, Hamid Ghayour ${ }^{*}$, Ali Salemi Golezani² ${ }^{2}$ Masoud Kasiri Asgarani ${ }^{1}$, \\ Iman Ebrahimzadeh ${ }^{1}$ \\ ${ }_{1}^{1}$ Advanced Materials Research Center, Department of Materials Engineering, Najafabad Branch, Islamic Azad University, Najafa- \\ bad, Iran. \\ ${ }^{2}$ Department of Materials Engineering, Karaj Branch, Islamic Azad University, Karaj, Iran. \\ *Corresponding Author's email: ghayour_ham@iust.ac.ir, Tell: +98 9132308300, Department of Materials Engineering, Najafabad \\ Branch, Islamic Azad University, Najafabad, Iran.
}

Received: 10.08 .2020

Accepted: 24.09 .2020

\begin{abstract}
In the current paper, the role of change in strain routes was investigated, along with the cold rolling of copper metal. Four different strain routes including, (a) unidirectional rolling, (b) reverse rolling, (C) two-stage cross-rolling, and (d) multi-stage cross-rolling, were utilized to investigate the effect of strain routes change on microstructure, texture evolution, and anisotropy. Tensile strength in the unidirectional rolling sample compared to the cross-rolling sample decreased in the direction of initial rolling from $364 \mathrm{MPa}$ to $340 \mathrm{MPa}$, in the direction of $45^{\circ}$ to the initial rolling from $359 \mathrm{MPa}$ to $347 \mathrm{MPa}$, and in the direction of perpendicular to the initial rolling from $371 \mathrm{MPa}$ to $360 \mathrm{MPa}$. Texture intensity also decreased from 1413 in the unidirectional rolling sample to 992 in the cross-rolled sample. The results demonstrated that by rolling in different routes, the cross-rolling has led to a more homogeneous microstructure, less anisotropy, and weaker texture.
\end{abstract}

Keywords: Reverse Rolling; Cross Rolling; Unidirectional Rolling; Copper; Change strain Route

\section{INTRODUCTION}

Change in strain routes during the deformation process affects metal plastic behaviors, such as the crystallographic texture evolution [1]. The main focus of strain route change is on the production of metal sheets with different textures and microstructures, indicating different properties [2]. The change in the strain route can be achieved by changing the rolling direction (RD) alternately. For instance, in the rolling process, four types of changes are considered for the strain route, being classified into (1) Unidirectional Rolling (UR), (2) Reverse Rolling (RR), (3) Two-Stage Cross-Rolling (TSCR), and (4) Multi-stage cross-rolling (MSCR) (Fig.1) [3,4].

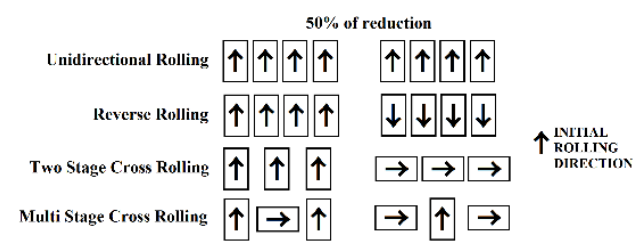

Fig. 1 Schematic of different rolling modes to show the change in strain route $[5,6]$

The strain route changes have a significant impact on the evolution of microstructure and texture during the rolling of metals, especially fcc metals, such as copper. Strain route changes in the rolling process due to the weaker texture created by the rolling can provide more homogeneous properties. Therefore, such changes can be a unique way to improve material properties [5]. In this regard, the effects on the materials as a result of changes in the direction of deformation are as follows: Changes in microstructure and crystallographic texture, Changes in plastic anisotropy, Changes in residual stress distribution [7, 9].

One of the solutions that may be suggested by changes in the strain route is to tailor the texture to control the formation of the desired texture components and eliminate undesired texture components [1, 8]. Additionally, Zhang et al. [10], concluded that changing the strain route could lead to an increase in the strength and ductility, grain refinement, and weaker texture. Goli et al. [11] also concluded that in the cross-rolled sheet sample, the grain size was smaller than in the unidirectionalrolled sheet and the reverse-rolled sheet; moreover, the effect of dynamic recrystallization could be observed. The local serrations of grain boundaries and the nucleation at pre-existing boundaries indicate the occurrence of discontinuous dynamic recrystallization (DDRX) mechanism. It should be noted that the number of dynamically recrystallized grains in cross-rolled samples is higher in comparison to unidirectional-rolled and reverse-rolled samples, which is leading to smaller grain size in cross-rolling specimens. In unidirectional-rolling specimens, the number of active sliding systems is less than in those of cross-rolling that is leading to a severe dislocation pile-up. In other words, cross rolling leads to the activation of numerous slip systems; consequently, it results in increasing cross slip possibility and recovery and recrystallization rates. Yang et al. [12] reported that in Al-Mg-Si alloys, a right combination of strength and flexibility was obtained by performing reverse rolling.

Cold working (e.g., rolling) on metals leads to orienting the microstructure along with the deformation. The orientation of 
the microstructure causes the orientation of mechanical properties; ultimately, it results in anisotropy occurrence. The value of $\mathrm{R}$, called the plastic anisotropy. The average amount of anisotropy in different directions, or $\mathrm{R}_{\mathrm{m}}$, which is also called vertical anisotropy, is equal to one $\left(R_{m}=1\right)$ for a perfectly isotropic material and indicates the strain and strength equality in the thickness and width directions of the sheet. The value of Rm depends on several factors, such as the chemical composition of the alloy, Young's modulus, primary grain size, amount of strain, and its angle to the rolling direction [13]. Plastic anisotropy (R) indicates the resistance of the sheet against any changes in the thickness. In other words, the ratio of true strain in the width direction $\left(\varepsilon_{\mathrm{w}}\right)$ to true strain in the thickness direction $\left(\varepsilon_{t}\right)$ in the uniaxial tension test is called the plastic anisotropy [14].

$$
R=\frac{\varepsilon_{w}}{\varepsilon_{t}}
$$

where:

\section{R-plastic anisotropy}

$\varepsilon_{\mathrm{W}}$ - true strain in the width direction

$\varepsilon_{t}$ - true strain in the thickness direction

Generally, the value of $R$ is not equal to one. It reveals the difference of the behavior in the two directions of the sheet (width and thickness)[14]. The average value of $R_{m}$ is defined as below:

$$
R_{m}=\frac{R_{0^{\circ}}+2 R_{45^{\circ}}+R_{90^{\circ}}}{4}
$$

where: $R_{m}$-average of anisotropy in different directions

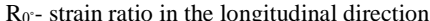

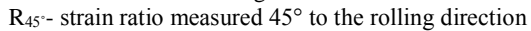

$\mathrm{R}_{90^{\circ}}$ - strain ratio in the transverse direction.

Samples are prepared at $0^{\circ}, 45^{\circ}$, and $90^{\circ}$ directions concerning the rolling direction of the sheet [12]. $\mathrm{R}_{\mathrm{m}}$ is weighted average of $\mathrm{r}$ values obtained in three directions: $0^{\circ}$ (parallel), $45^{\circ}$ (diagonal), and $90^{\circ}$ (transverse) to the rolling direction. Planar anisotropy (eq.(3)) is another significant indicator that one of the applications of which is the expression of the degree of earring of the edges that occur on the sides of the deep drawing specimens $[15,16]$. For a perfectly isotropic sheet, the following equations of $\Delta R=0$ and $R_{m}=1$ must apply. In some cases, the orientation of the mechanical properties is undesirable and must be controlled [13]. One of the ways to reduce the value of $\mathrm{R}_{\mathrm{m}}$ and control the anisotropy phenomena is recrystallization and annealing heat treatment $[17,18]$.

$\Delta R=\frac{R_{0^{\circ}}-2 R_{45^{\circ}}+R_{90^{\circ}}}{2}$

where: $\Delta \mathrm{R}$ - planar anisotropy

$\mathrm{R}_{0^{\circ} \text { - }}$ strain ratio in the longitudinal direction

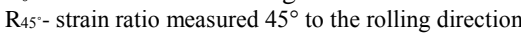

$\mathrm{R}_{90^{\circ} \text { - }}$ strain ratio in the transverse direction.

Many researchers have investigated the effect of strain routes in the cold rolling process on microstructure, mechanical properties, anisotropy, and texture of various alloys. However, the effect of different strain routes in the $\mathrm{C} 11000$ copper alloy on the same four features has not been studied altogether. Therefore, in the present study, the effect of various strain routes in cold rolling (including unidirectional rolling, cross rolling, and reverse rolling) on the mentioned four features of copper alloy $\mathrm{C} 11000$ is investigated.

\section{MATERIAL AND METHODS}

All samples were subjected to a complete annealing process at $600{ }^{\circ} \mathrm{C}$ and 1 hour respectively temperatures and times. Samples were subjected to the rolling process according to the routes provided in Table 2 . These routes are displayed schematically in Fig. 2. A rolling machine performed cold rolling with two rollers that have a diameter of $350 \mathrm{~mm}$. The rolling speed was 10 meters per minute. The final thickness of the rolled sheets was $2.5 \mathrm{~mm}$. Finally, a total $50 \%$ reduction in thickness was observed in sheets.

Table 1 Chemical analysis of C11000 alloy

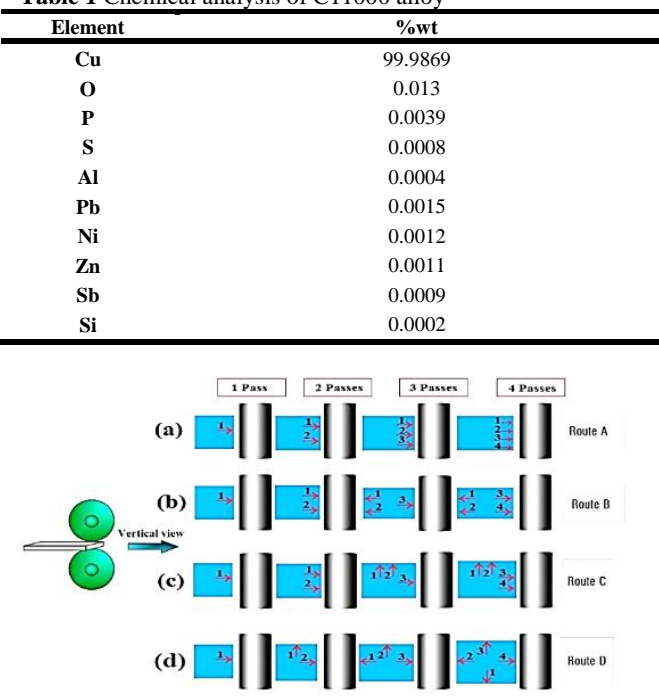

Fig. 2 Schematic of different rolling routes

The rolled specimens in three different planes (are shown in Fig.3), were cut and mounted, and the polishing process was performed and were etched in a solution $(150 \mathrm{cc} \mathrm{Hcl}+$ $10 \mathrm{grFeCl}_{3}+100 \mathrm{cc} \mathrm{H}_{2} \mathrm{O}$ ) and examined under an optical microscope. Tensile test samples were prepared according to ASTM E8M standard from different cycles of rolled parts to investigate the difference between mechanical and anisotropy properties in three directions of 0,45 , and 90 degrees with respect to the initial rolling direction according to ASTM E517 and ISO 10113 (are shown in Fig.4). Texture measurements were carried out by a Philips X'pert MPD X-ray texture diffractometer that is utilizing $\mathrm{Cu} \mathrm{K} \alpha$ radiation.

Table 2 Schedule for different routes of the rolling process (final thickness as $2.5 \mathrm{~mm}$ )

\begin{tabular}{|c|c|}
\hline Samples & Deformation steps \\
\hline A & $\begin{array}{c}\text { Unidirectional Rolling (UR) } \\
\text { reduction: } 50 \% \text { in RD }\end{array}$ \\
\hline B & $\begin{array}{c}\text { Reverse Rolling (RR) } \\
\text { reduction: } 25 \% \text { in RD and 25\% in RR }\end{array}$ \\
\hline C & $\begin{array}{c}\text { Two Stage Cross Rolling (TSCR) } \\
\text { reduction: } 25 \% \text { in RD and 25\% in CR }\end{array}$ \\
\hline D & $\begin{array}{c}\text { Multi Stage Cross Rolling (MSCR) } \\
\text { reduction:12.5\% in RD + 12.5\% in CR+ 12.5\% RR+ } \\
12.5 \% \text { CR }\end{array}$ \\
\hline
\end{tabular}




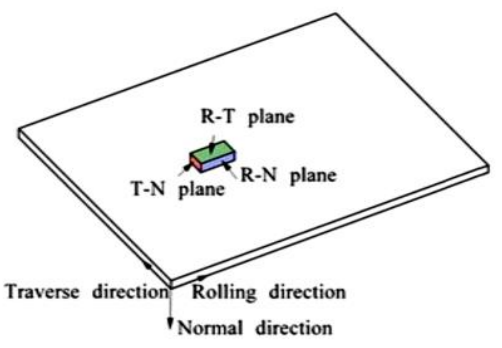

Fig. 3 Illustrations of sampling location in rolling samples

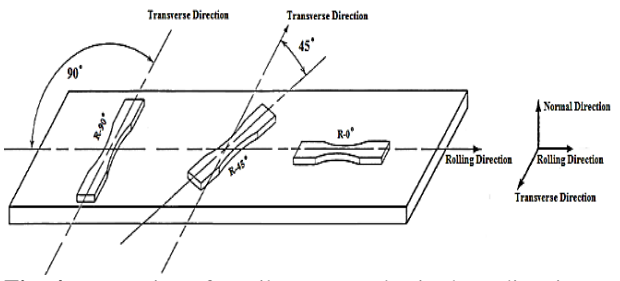

Fig. 4 Preparation of tensile test samples in three directions of $0^{\circ}, 45^{\circ}$, and $90^{\circ}$

\section{RESULTS AND DISCUSSION}

\section{Microstructure}

The microstructure images of three sections of these specimens are illustrated in Fig.5, Fig.6, Fig.7, and Fig.8.

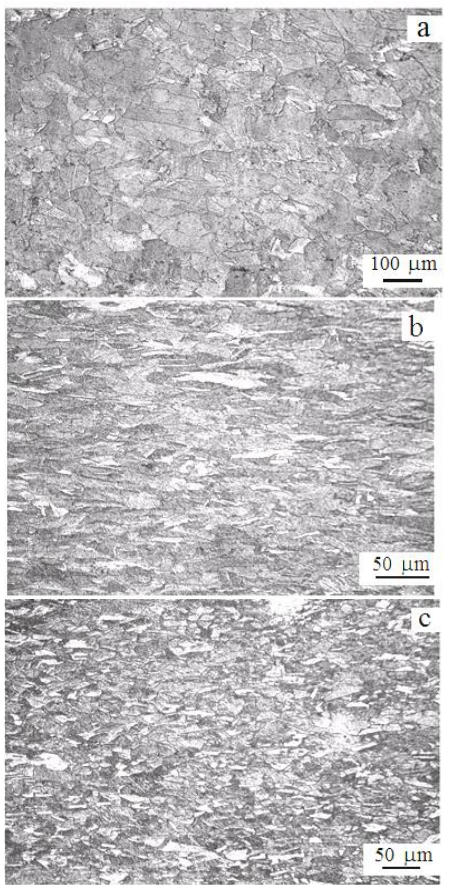

Fig. 5 Optical micrographs related to A sample and in sections (a) of the R-T plane, (b) the R-N plane, and (c) the T-N plane

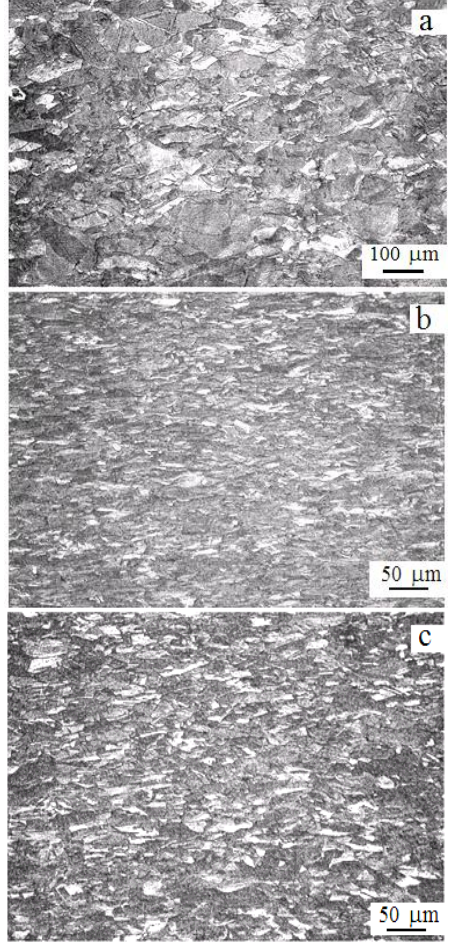

Fig. 6 Optical micrographs related to B sample and in sections (a) of the R-T plane, (b) the R-N plane, and (c) the T-N plane.

In rolled specimens in different routes, the grains were elongated according to the amount of strain and its direction in the last rolling pass, and bands were formed with different widths. In the B sample, which reversed the rolling direction, the grain size got decreased in comparison to the A sample. Additionally, the average length of the grains decreased; however, the width of the grains showed little variations (Table 3). By increasing cross rolling, the grain size decreased. In crossrolled specimens $(\mathrm{C}$ and $\mathrm{D})$, the aspect ratio was slightly different on the two planes of TN and RN. Samples with higher cross rolling had a more homogeneous microstructure. Furthermore, twinning was observed in all samples of rolled copper. In cross-rolling and reverse-rolling specimens, the mentioned twinnings are more common in general.

Dislocation slip is known as the primary ruling mechanism during plastic deformation, which leads to the formation of dislocation cells, dislocation walls, or micro bands, depending on the imposed strain and initial orientation. Moreover, shear bands occur as a specific manifestation of local plastic instability at medium to large strains $[19,20]$. In the microstructure images of rolled samples, shear bands are visible. Sawas et al. [6] also observed shear bands in microstructure images of rolled copper specimens. They indicated that by performing two-step cross rolling, the direction of shear bands changed in comparison to the unidirectional rolling sample, and in multistep cross rolling, shear bands were present in both directions. The mentioned shear bands that have been formed in two different directions during unidirectional and cross rolling are 
also observed in other researchers' studies, including Pospiech [21].

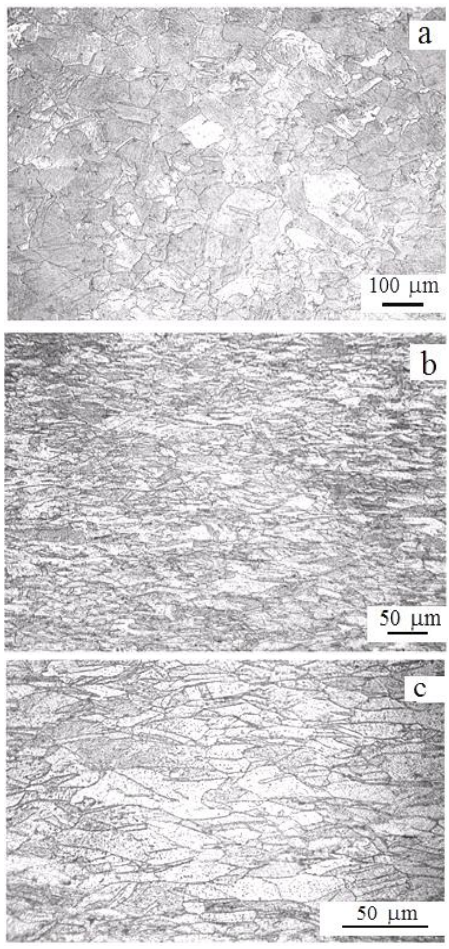

Fig. 7 Optical micrographs related to $\mathrm{C}$ sample and in sections (a) of the R-T plane, (b) the R-N plane, and (c) the T-N plane

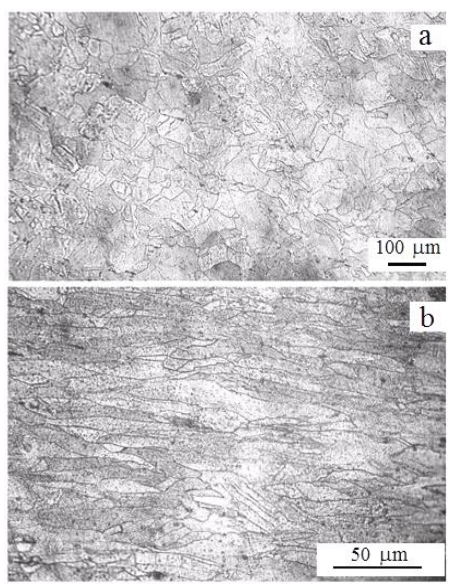

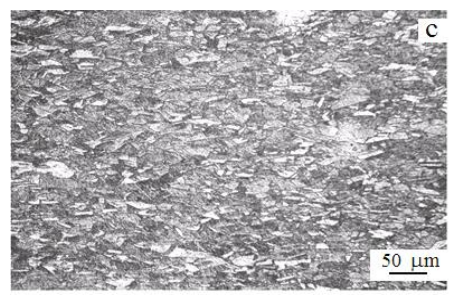

Fig. 8 Optical micrographs related to D sample and in sections (a) of the R-T plane, (b) the R-N plane, and (c) the T-N plane. Table 3 Average grain size and aspect ratio in R-T, R-N, and $\mathrm{T}-\mathrm{N}$ planes in rolling samples

\begin{tabular}{|c|c|c|c|c|c|c|}
\hline $\begin{array}{c}\text { sample } \\
\text { name }\end{array}$ & \multicolumn{2}{|c|}{ R-N plane } & \multicolumn{2}{c|}{ T-N plane } & \multicolumn{2}{|c|}{ R-T plane } \\
\cline { 2 - 7 } & $\begin{array}{c}\text { aspect } \\
\text { ratio }\end{array}$ & $\begin{array}{c}\text { average } \\
\text { grain } \\
\text { length } \\
(\mu \mathrm{m})\end{array}$ & $\begin{array}{c}\text { aspect } \\
\text { ratio }\end{array}$ & $\begin{array}{c}\text { average } \\
\text { grain } \\
\text { length } \\
(\mu \mathrm{m})\end{array}$ & $\begin{array}{c}\text { aspect } \\
\text { ratio }\end{array}$ & $\begin{array}{c}\text { average } \\
\text { grain } \\
\text { length } \\
(\mu \mathrm{m})\end{array}$ \\
\hline A & 3.97 & 23.08 & 6.65 & 40.33 & 2.44 & 35.47 \\
\hline B & 3.69 & 21.80 & 5.41 & 33.25 & 2.50 & 33.72 \\
\hline C & 4.09 & 25.47 & 5.72 & 31.28 & 2.17 & 33.02 \\
\hline D & 5.04 & 27.15 & 5.90 & 29.74 & 2.65 & 31.01 \\
\hline
\end{tabular}

\section{Tensile test}

The diagrams obtained from the tensile test in three directions of 0,45 , and 90 degrees relative to the first rolling direction (RD) are illustrated in Fig.9; moreover, the comparison diagrams of strength and elongation in different rolling routes are shown in Fig.10 (a) and (b), respectively. As can be observed, cold rolling operations on different routes resulted in increased strength and reduced elongation in all three directions of tensile test 0,45 , and 90 degrees. The mentioned fact was due to an increase in work hardening, an increase in the density of dislocation, and a decrease in grain size. Additionally, the highest strength in these samples occurred in A and B. The strength in the two directions of 0 and 45 degrees in the B sample regarding the reverse rolling was more than the A sample regarding the unidirectional rolling. Moreover, the elongation increased in all the three directions in the B sample (reverse rolling) in comparison to A sample. In general, the use of the reverse-rolling process in copper alloy C11000 increased the strength and elongation to the failure property in comparison to unidirectional rolling samples; furthermore, it improved the mechanical properties of reverse rolling compared to the unidirectional one. The reason for this can be attributed to grain refinement, dislocations interaction, and lower aspect ratio (relation between the length and width of the grain) in the reverse-rolling specimen in comparison to unidirectional one. Sabat et al. [22] obtained similar results for unidirectional and reverse rolling in titanium alloys. They confirmed the increase in dislocation density and energy stored in reverse rolling to unidirectional rolling. 


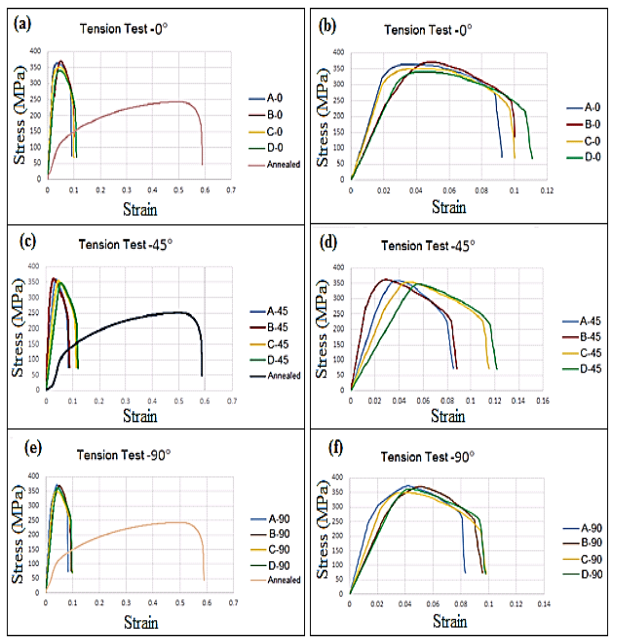

Fig. 9 Diagram of the tensile test in the direction of (a) and (b) $0^{\circ}$, (c) and (d) $45^{\circ}$, (e) and (f) $90^{\circ}$ with respect to the direction of first rolling in the rolled samples.

It can also be attributed to grain refinement, grain size reduction, and lower aspect ratio in the reverse rolling sample compared to that of unidirectional rolling, as well. In the $\mathrm{C}$ and D samples, in which different cross rolling occurred, the tensile and yield strengths were less than the unidirectional rolling (sample A) and reverse rolling (sample B). (a)

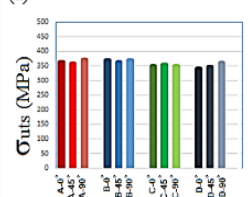

(b)

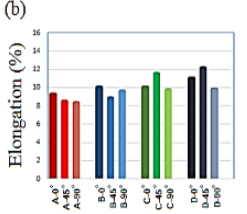

Fig. 10 Comparison (a) of tensile strength and (b) elongation in rolled specimens in different routes

Moreover, the elongation to failure property of these samples increased compared to A and B samples. According to the research of Ostafin et al. [8], the change in the direction of plastic strain on copper sheets caused significant changes in the distribution of grain orientation (crystal texture) and the microstructure of the material; these changes led to changes in plastic behavior and mechanical properties, such as strength and softness of the deformation. They found that changing the strain route and cross rolling of copper sheets resulted in forming a combination of desirable textures, reducing undesirable textures, and creating more uniform properties.

Reduction in grain size could lead to an increase in strength in cross-rolling specimens, whereas cross rolling reduced strength and increased the elongation relative to unidirectional rolling. The stated fact may be due to weaker crystalline texture and dynamic recrystallization due to the strain route change. The achieved results were also observed in the research of Zhang Hua [10] et al. and Rout [7] et al.

\section{Anisotropy}

The values of $R_{m}$ anisotropy in the rolled samples were calculated according to the strain obtained in the longitudinal and transverse directions of the tensile test samples.

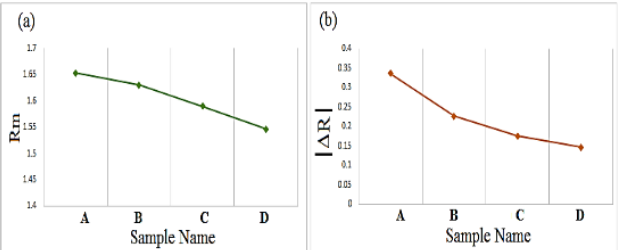

Fig. 11 Comparison diagrams between values of (a) planar anisotropy in rolled specimens, (b) anisotropy of rolled specimens

According to the obtained values of $\Delta R$ and $R_{m}$ for rolling samples in different routes, the diagrams in Fig.11, it can be concluded that the values $|\Delta R|$ and $R m$ decreased by changing the strain direction and also occurring cross rolling. Thus, similar to the results obtained by Goli et al. [11], changing the strain direction and cross rolling has been an effective method to reduce the anisotropic mechanical properties of $\mathrm{C} 11000$ copper alloy sheet. These results are in line with those of other researchers, including Wronski et al. [9] and Rout et al. [7]. Therefore, changing the strain direction in the C11000 copper alloy sheet can lead to the production of a sheet with relative isotropic properties in different directions in comparison to unidirectional rolling.

\section{Microhardness test}

The Vickers microhardness test was performed on rolled specimens on three planes of RT, TN, and RN and compared in Fig.12. In this regard, the amounts of microhardness on the TN plane is higher than the other two planes. Additionally, in all samples, the values of microhardness on the RT plane is less than the other two planes. The microhardness values obtained in this experiment are in good agreement with the microstructure and grain size obtained from the metallography of the rolled samples.

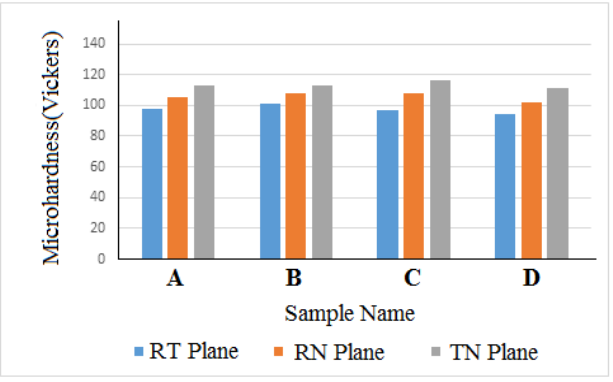

Fig. 12 Comparison diagrams of the values for microhard-ness in different routes and planes

\section{Crystallographic texture}

Changing the deformation route has a major effect on the formation of cold rolling texture. The $\left(\begin{array}{lll}1 & 1 & 1\end{array}\right)$ pole figures for the deformed specimens in four different routes are presented in Fig.13. As observed, the texture present in A and B samples represents the texture of FCC metals, with the medium and high stacking fault energy. Texture in copper is characterized by compounds, including $\mathrm{Cu}\{112\}(111)$, Bs $\{110\}(112)$, and $\mathrm{S}\{123\}(634)$ [5]. The texture of $\mathrm{D}$ and $\mathrm{C}$ specimens are significantly different from the corresponding texture of $\mathrm{A}$ and B specimens for copper. The texture of cross-rolling specimens (C and D) is relatively weaker than that of unidirectional- 
rolling and reverse-rolling specimens. As demonstrated in Fig.13, which is presented the pole figure of the rolling specimens in different routes, the unidirectional-rolling specimen has the highest intensity; additionally, the texture intensity in the reverse rolling is less than the unidirectional rolling and more than the cross rolling. The multi-stage cross-rolling specimen has the lowest texture intensity. These results are similar to results of other researchers $[23,24]$.

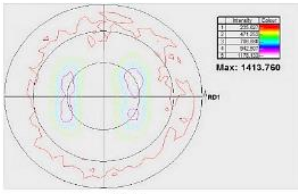

(a)

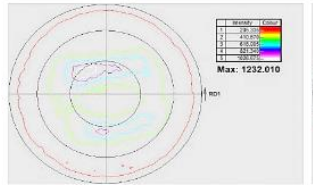

(c)

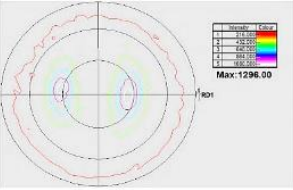

(b)

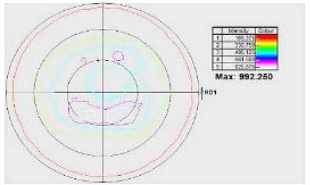

(d)
Fig. 13 Pole figures (111) of (a) A, (b) B, (c) C, and (d) D samples

\section{CONCLUSION}

Changes in mechanical properties, anisotropy, microstructure, and texture of $\mathrm{C} 11000$ copper after unidirectional, reverse rolling, and cross rolling are investigated in the present study. The microstructure of the rolled samples includes the stretched grains along the last rolling direction, which is indicating the deformation band and reduced grain size. Changing the routes of plastic strain on the copper sheet causes significant changes in the material's microstructure. Cross rolling in C and D samples reduces grain size compared to unidirectional and reverse rolling. Grains are also stretched along with the last steps of the rolling. Changing the strain routes and performing cross rolling in copper metal reduce the strength compared to unidirectional and reverse rolling samples (from $371 \mathrm{Mpa}$ to $340 \mathrm{Mpa}$ ) and increase the ductility to some extent (from 8.5 to 12). Plastic anisotropy in cross-rolling samples is less than unidirectional and reverse rolling specimens. X-Ray results reveal that texture intensity in rolling specimens in different routes is not equal. The texture intensity in cross-rolling specimens (992) is lower than in unidirectional-rolling (1413) and reverse-rolling (1296) specimens. One of the reasons for the lower anisotropy of cross-rolling specimens in comparison to those of unidirectional and reverse rolling can be the more moderate texture intensity in these specimens.

\section{REFERENCES}

1. S. Suwas, A.K. Singh: Materials Science and Engineering A, 356(1-2), 2003, 368-371. https://doi.org/10.1016/S0921-5093(03)00149-7.

2. W. Chen,Y. Lv, H. Wang, X. Zhang, C. Chen, Y.C. Lin, K. Zhoua: Materials Science and Engineering: A, 769, 2020, 138516.

https://doi.org/10.1016/i.msea.2019.138516.

3. M. Benke, B. Schweitzer, A. Hlavacs, V. Mertinger: Metals, 10(2), 2020, 192. https://doi.org/10.3390/met10020192.

4. S. Suwas, N. Gurao: Comprehensive Materials Processing,

3, 2014, 81-106.
https://doi.org/10.1016/B978-0-08-096532-1.00308-3.

5. N. Gurao, S. Sethuraman, S. Suwas: Materials Science and Engineering A, 528(25-26), 2011, 7730-7750.

https://doi.org/10.1016/j.msea.2011.06.062.

6. S. Suwas, A. K. Singh, K. Narasimha Rao, T. Singh: Carl Hanser Verlag, Munchen Z. Metallkd, 93(9), 2002, 918-927. https://doi.org/10.3139/146.020918.

7. M. Rout, S. K. Pal, S. B. Singh: Cross Rolling: A Metal Forming Process, In: Modern Manufacturing Engineering, Materials Forming, Machining and Tribology, Springer International Publishing Switzerland, 2015, 41-66. https://doi.org/10.1007/978-3-319-20152-8 2.

8. M. Ostafin, J. Pospiech, R.A. Schwarzer: Solid State Phenomena, 105, 2005, 309-314.

https://doi.org/10.4028/www.scientific.net/SSP.105.309.

9. S. Wronski, M. Wrobel, A. Baczmanski, K. Wierzbanowski: Materials Characterization, 77, 2013, 116-126.

https://doi.org/10.1016/j.matchar.2013.01.005.

10. H. Zhang, G. Huang, H. J. Roven, L. Wang, F. Pan: Materials and Design, 50, 2013, 667-673.

https://doi.org/10.1016/j.matdes.2013.03.053.

11. F. Goli, R. Jamaati: Materials Research Express, 6(6), 2019.

https://doi.org/10.1088/2053-1591/ab0a1f.

12. H. Yang, I. Widiantara, Y. Ko: Materials Letters, 213, 2018, 54-57.

https://doi.org/10.1016/j.matlet.2017.11.012

13. W. F. Hosford and R. M. Caddell: Metal Forming Mechanics And Metallurgy, Third Edition, Cambridge University Press, 2007.

14. Dieter G.E.: Workability Testing Techniques. ASM Handbook. Vol. 8, 1999 .

15. ASTM E517: Standard Test Method for Plastic Strain Ratio $\mathrm{r}$ for Sheet Metal, ASTM International, Conshohocken, 2000

16. ISO 10113: Metallic Materials- Sheet and strip- Determination of plastic strain ratio, International Standard, Switzerland, 2006.

17. X. Chen, L. Wang, R. Xiao, X. Zhong, G. Huang, Q. Liu: Journal of Alloys and Compounds, 604, 2014, 112-116.

https://doi.org/10.1016/j.jallcom.2014.03.093.

18. Y. Ma et al.: Progress in Natural Science: Materials International, 28(6), 2018, 711-717.

https://doi.org/10.1016/j.pnsc.2018.10.004.

19. Y. Xu, H. Jiao, W. Qiu, R. D. K. Misra, J. Li: Materials,11(7), 2018,1161. https://doi.org/10.3390/ma11071161.

20. A. Sonboli, M. R. Toroghinejad, H. Edris and J. A. Szpunar: International Journal of Iron \& Steel Society of Iran, 12(2), 2015, 1-6.

21. J. Pospiech: Archives of Metallurgy and Materials, 53(1), 2008, 83-87.

22. R. K. Sabat, S. K. Sahoo, B. D. Bishoyi, N. Bibhanshu, S. Suwas: Philosophical Magazine Letters, 97(7), 2017, 273-279. https://doi.org/10.1080/09500839.2017.1341647.

23. D. K. Liu, G. S. Huang, G. L. Gong, G. G. Wang, F. S. Pan: Transactions of Nonferrous Metals Society of China, 27(6), 2017, 1306-1312.

https://doi.org/10.1016/S1003-6326(17)60151-1.

24. Y. Chino, K. Sassa, A. Kamia, M. Mabuchi: Materials Transactions, 47(10), 2006, 2555-2560.

https://doi.org/ 10.2320/matertrans.47.2555. 